\title{
OPEN Low CYP24A1 mRNA expression and its role in prognosis of breast cancer
}

Received: 18 April 2019

Accepted: 9 September 2019

Published online: 23 September 2019

\author{
Hongqiao Cai ${ }^{1}$, Yan Jiao ${ }^{1}{ }^{1}$, Yanqing $\mathrm{Li}^{2}$, Zhaoying Yang ${ }^{3}$, Miao He ${ }^{4}$ \& Yahui Liu ${ }^{1}$
}

Breast cancer is the most common malignant cancer in women. CYP24A1 expression regulates cellular response to vitamin $D$, which has antitumor effects against breast cancer. This study aimed to identify the correlation between CYP24A1 mRNA expression and prognosis of breast cancer. This study enrolled 1102 patients, including 1090 females and 12 males, from TCGA-BRCA cohort. The Cancer Genome Atlas database was used to study CYP24A1 mRNA expression in breast cancer, and Chi-squared tests were performed to test the correlation between clinical features and CYP24A1 expression. The prognostic value of CYP24A1 in breast cancer was assessed using Kaplan-Meier curves and Cox analysis. Low CYP24A1 expression was associated with age, molecular subtype, ER, PR, HER2, menopause status, $\mathrm{N}$ classification, vital status, overall survial and relapse-free survival. CYP24A1 presented a moderate diagnostic ability in breast cancer. Furthermore, low CYP24A1 expression was correlated with poor prognosis. CYP24A1 was an independent risk factor for breast cancer. CYP24A1 plays an important role in prognosis of breast cancer. CYP24A1 has the potential to be a biomarker, especially in predicting prognosis.

Breast cancer is one of the three most common cancers worldwide and has the highest incidence rate of malignancy in women ${ }^{1}$. For breast cancer, biomarkers are particularly useful in identification, diagnosis and predicting prognosis ${ }^{2}$. Although many biomarkers have been in use, they are limited to certain molecular types of breast cancer, thus prompting searches for new biomarkers to predict prognosis on a larger scale.

Vitamin D, the precursor to the potent steroid hormone, calcitriol, has potential anti-proliferative effects on breast cancers ${ }^{3,4}$. A review conducted by Feldman et al. has indicated the increased risk of developing cancer with vitamin $\mathrm{D}$ deficiency ${ }^{3}$. However, an agreement has not been reached yet whether high or low vitamin D is associated with breast cancer ${ }^{4}$. The vitamin $\mathrm{D}$ receptor is expressed in different types of human breast cancers $^{5}$, and active vitamin D has several antitumor effects ${ }^{6}$. The 24-hydroxylase (CYP24A1) enzyme inactivates $1 \alpha, 25$-dihydroxyvitamin D3 (1,25D3), the physiologically active vitamin D metabolite, which regulates cellular response to vitamin $\mathrm{D}^{7,8}$. Considering the high heterogeneity of vitamin $\mathrm{D}$ signaling in breast cancer, it is unknown whether vitamin D resistance through VDR methylation or CYP24A1 amplification during tumor progression would emerge for one individual's breast cancer9. Thus, CYP24A1 is thought to play an important role in breast cancer through the vitamin D signaling pathway. Recently, CYP24A1 has been studied in many diseases, and it is identified as a potential biomarker for cancers, including lung adenocarcinoma and colorectal cancer ${ }^{10,11}$.

Herein, we evaluated the correlation between CYP24A1 expression in breast cancer and clinicopathologic features through analysis of data from The Cancer Genome Atlas (TCGA) database. We further assessed the independent prognostic value of CYP24A1 expression for overall and relapse-free survival.

\section{Results}

Patient features. From TCGA database, we obtained RNA expression data and related clinical information. In total, 1102 patients, including 1090 females and 12 males, with breast cancer were analyzed. Moreover, 589 patients were younger than 60 years old, and 513 patients were older than 60 years old. The background of patients was TCGA-BRCA cohort. The average follow-up time of patients for overall survival and relapse-free

${ }^{1}$ Department of Hepatobiliary and Pancreatic Surgery, The First Hospital of Jilin University, Changchun, Jilin, 130021, P.R. China. ${ }^{2}$ Department of Pathophysiology, College of Basic Medical Sciences, Jilin University, Changchun, Jilin, 130021, P.R. China. ${ }^{3}$ Department of Breast Surgery, China-Japan Union Hospital of Jilin University, 126 Xiantai Street, Changchun, 130033, P. R. China. 'Department of Anesthesia, The Second Hospital of Jilin University, Changchun, 130022, P. R. China. Correspondence and requests for materials should be addressed to Z.Y. (email: zhaoyingyang@163.com)orY.L. (email: liuyahui2008@yeah.net) 


\begin{tabular}{|c|c|}
\hline Characteristics & Numbers of sample size(\%) \\
\hline \multicolumn{2}{|l|}{ Age } \\
\hline$<60$ & $589(53.45)$ \\
\hline$>=60$ & $513(46.55)$ \\
\hline \multicolumn{2}{|l|}{ Gender } \\
\hline Female & $1090(98.73)$ \\
\hline Male & $12(1.09)$ \\
\hline NA & $2(0.18)$ \\
\hline \multicolumn{2}{|l|}{ Histological type } \\
\hline Infiltrating Ductal Carcinoma & $790(71.56)$ \\
\hline Infiltrating Lobular Carcinoma & $204(18.48)$ \\
\hline Other & $107(9.69)$ \\
\hline NA & $3(0.27)$ \\
\hline \multicolumn{2}{|l|}{ Molecular subtype } \\
\hline Basal & $142(12.86)$ \\
\hline Her2 & $67(6.07)$ \\
\hline LumA & $422(38.22)$ \\
\hline LumB & $194(17.57)$ \\
\hline Normal & $24(2.17)$ \\
\hline NA & $255(23.1)$ \\
\hline \multicolumn{2}{|l|}{ ER } \\
\hline Indeterminate & $2(0.18)$ \\
\hline Negative & $239(21.65)$ \\
\hline Positive & $813(73.64)$ \\
\hline NA & $50(4.53)$ \\
\hline \multicolumn{2}{|l|}{ PR } \\
\hline Indeterminate & $4(0.36)$ \\
\hline Negative & $345(31.25)$ \\
\hline Positive & $704(63.77)$ \\
\hline NA & $51(4.62)$ \\
\hline \multicolumn{2}{|l|}{\begin{tabular}{|l|} 
HER2 \\
\end{tabular}} \\
\hline Equivocal & $180(16.3)$ \\
\hline Indeterminate & $12(1.09)$ \\
\hline Negative & $565(51.18)$ \\
\hline Positive & $164(14.86)$ \\
\hline NA & $183(16.58)$ \\
\hline \multicolumn{2}{|l|}{ Menopause status } \\
\hline Inde & $34(3.08)$ \\
\hline Peri & $40(3.62)$ \\
\hline Post & 706 (63.95) \\
\hline Pre & $231(20.92)$ \\
\hline NA & $93(8.42)$ \\
\hline \multicolumn{2}{|l|}{ T classification } \\
\hline $\mathrm{T} 1$ & 281 (25.45) \\
\hline $\mathrm{T} 2$ & 640 (57.97) \\
\hline T3 & $138(12.5)$ \\
\hline $\mathrm{T} 4$ & $40(3.62)$ \\
\hline $\mathrm{TX}$ & $3(0.27)$ \\
\hline NA & $2(0.18)$ \\
\hline \multicolumn{2}{|l|}{$\mathrm{N}$ classification } \\
\hline No & $516(46.74)$ \\
\hline N1 & $367(33.24)$ \\
\hline N2 & $120(10.87)$ \\
\hline N3 & $79(7.16)$ \\
\hline $\mathrm{NX}$ & $20(1.81)$ \\
\hline NA & $2(0.18)$ \\
\hline \multicolumn{2}{|l|}{ M classification } \\
\hline M0 & 917 (83.06) \\
\hline Continued & \\
\hline
\end{tabular}




\begin{tabular}{|c|c|}
\hline Characteristics & Numbers of sample size(\%) \\
\hline M1 & $22(1.99)$ \\
\hline MX & $163(14.76)$ \\
\hline NA & $2(0.18)$ \\
\hline \multicolumn{2}{|l|}{ Stage } \\
\hline I & $182(16.49)$ \\
\hline II & $626(56.7)$ \\
\hline III & $252(22.83)$ \\
\hline IV & $20(1.81)$ \\
\hline $\mathrm{X}$ & $14(1.27)$ \\
\hline NA & $24(0.91)$ \\
\hline \multicolumn{2}{|l|}{ Lymph node status } \\
\hline NO & $28(2.54)$ \\
\hline YES & $697(63.13)$ \\
\hline NA & $379(34.33)$ \\
\hline \multicolumn{2}{|l|}{ Margin status } \\
\hline Close & $31(2.81)$ \\
\hline Negative & $922(83.51)$ \\
\hline Positive & $79(7.16)$ \\
\hline NA & $72(6.52)$ \\
\hline \multicolumn{2}{|l|}{ Vital status } \\
\hline Deceased & $155(14.04)$ \\
\hline Living & $947(85.78)$ \\
\hline NA & $2(0.18)$ \\
\hline \multicolumn{2}{|l|}{ Radiation therapy } \\
\hline NO & $445(40.31)$ \\
\hline YES & $557(50.45)$ \\
\hline NA & $102(9.24)$ \\
\hline \multicolumn{2}{|c|}{ Neoadjuvant treatment } \\
\hline $\mathrm{NO}$ & $1088(98.55)$ \\
\hline YES & $13(1.18)$ \\
\hline NA & $3(0.27)$ \\
\hline \multicolumn{2}{|c|}{ Targeted molecular therapy } \\
\hline NO & $46(4.17)$ \\
\hline YES & $533(48.28)$ \\
\hline NA & $525(47.55)$ \\
\hline \multicolumn{2}{|l|}{ Sample type } \\
\hline Metastatic & $7(0.63)$ \\
\hline Primary Tumor & $1097(99.37)$ \\
\hline \multicolumn{2}{|l|}{ Overall survival } \\
\hline NO & $933(85.83)$ \\
\hline YES & $154(14.17)$ \\
\hline \multicolumn{2}{|c|}{ Recurrence-free survival } \\
\hline NO & $816(89.47)$ \\
\hline YES & $96(10.53)$ \\
\hline \multicolumn{2}{|l|}{ CYP24A1 } \\
\hline High & $647(58.61)$ \\
\hline Low & 457 (41.39) \\
\hline
\end{tabular}

Table 1. Demographic and clinical characteristics of TCGA cohort. Abbreviation: NA, not available. Note: Inde, indeterminate menopause (neither Pre or Postmenopausal). Peri, perimenopause (6-12 months since last menstrual period). Post, postmenopause (prior bilateral ovariectomy OR $>12$ mo since last menstrual period with no prior hysterectomy). Pre, prememopause ( $<6$ months since last menstrual period and no prior bilateral ovariectomy and not on estrogen replacement).

survival is 1261.6 days and 1262.8 days respectively, and the number of events was 154 . The detailed clinical characteristics of these corresponding patients are shown in Table 1, including molecular subtype, TNM stage, survival status and radiation therapy. 

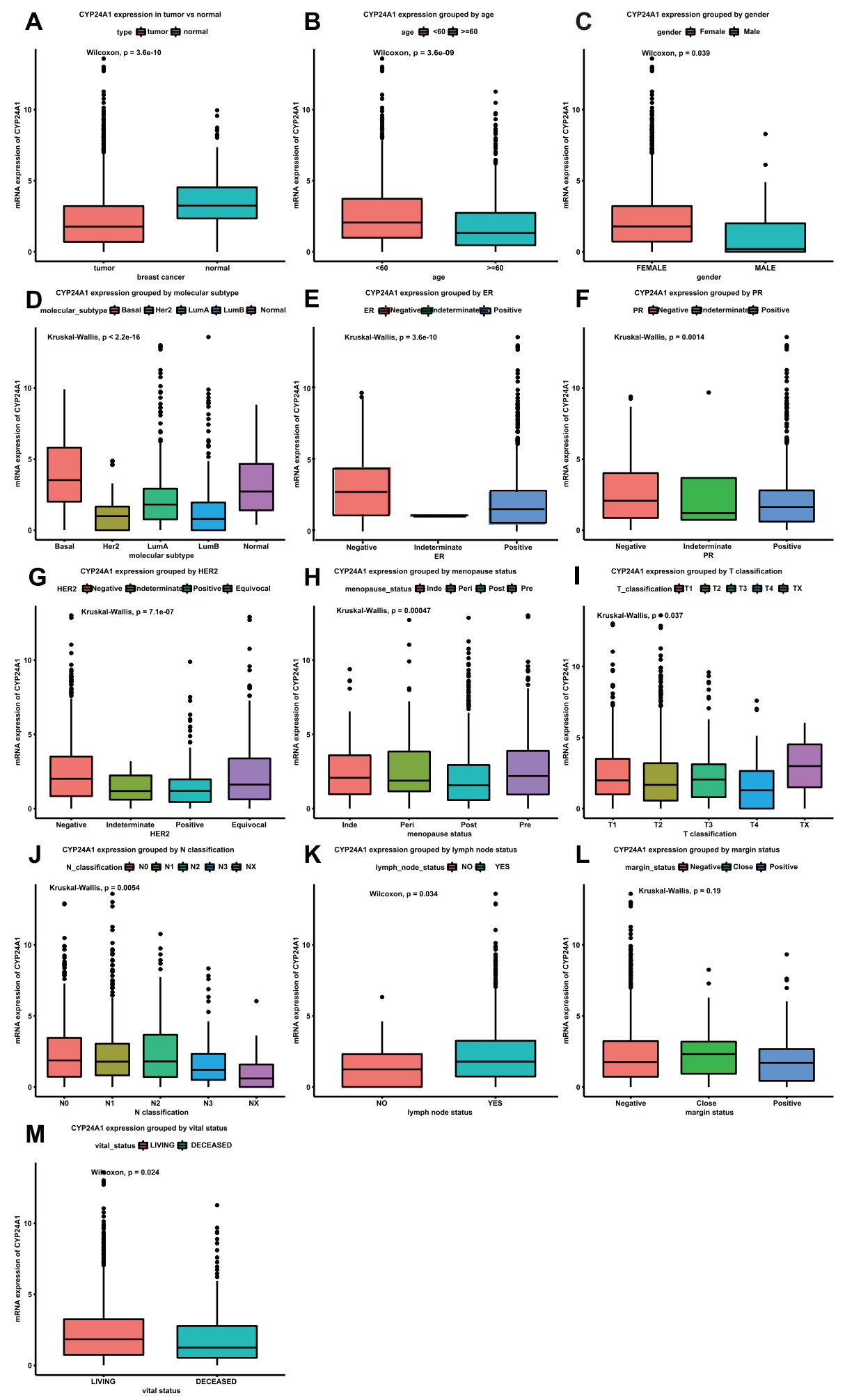

Figure 1. Different CYP24A1 expression levels in the boxplot. CYP24A1 expression in tumor and normal tissue. Expression is grouped by age, gender, molecular subtype, ER, PR, HER2, menopause status, T classification, $\mathrm{N}$ classification, lymph node status, margin status and vital status.

Low CYP24A1 mRNA expression in breast cancer. As shown in Fig. 1A, the mRNA expression of CYP24A1 in breast tumor tissue was significantly lower than that in breast normal tissue $(p=3.6 \mathrm{e}-10)$. Furthermore, different CYP24A1 expression levels were observed in groups based on age, gender, molecular subtype, ER, PR, HER2, menopause status, T classification, $\mathrm{N}$ classification, lymph node status, margin status and 

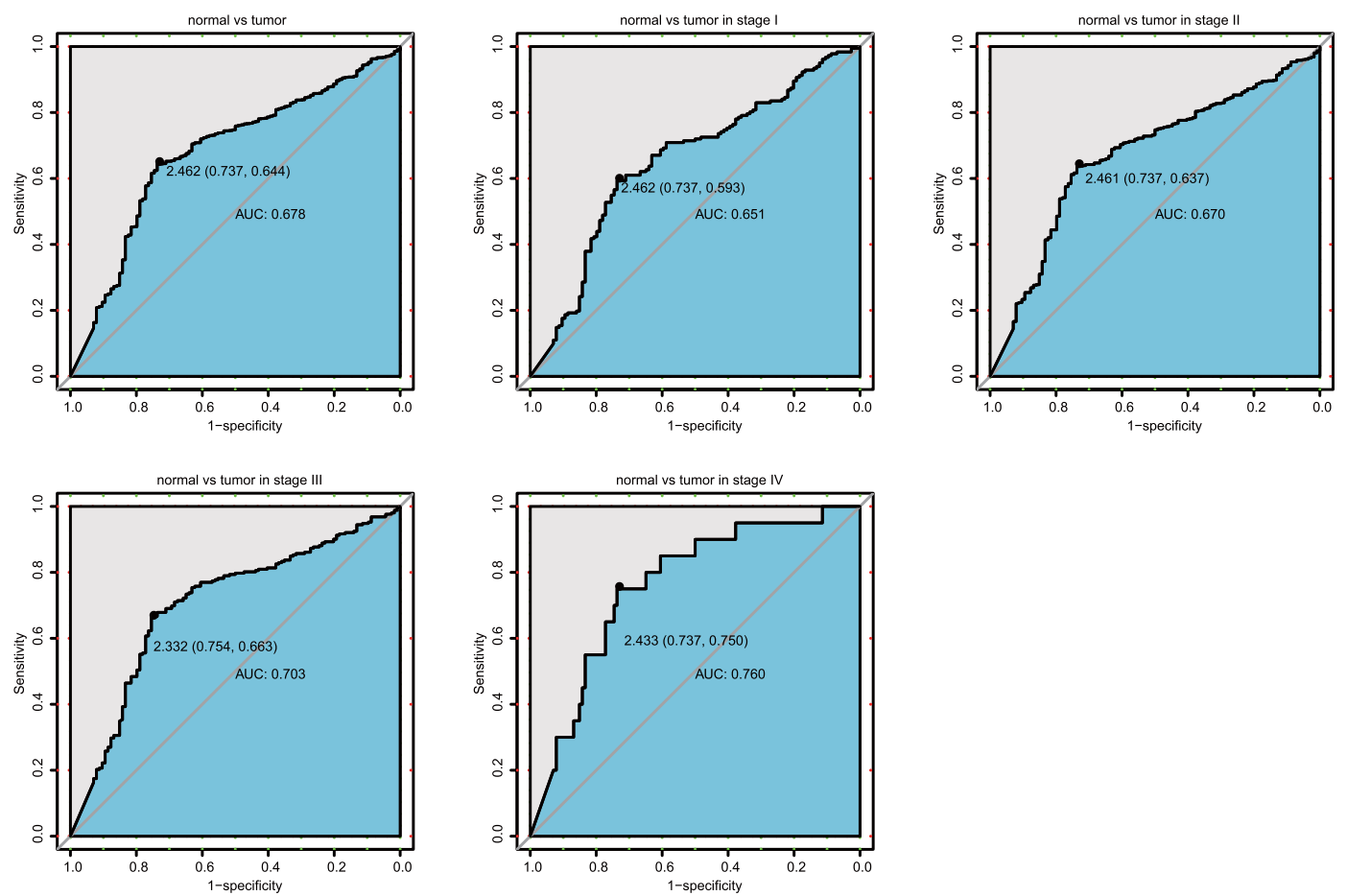

Figure 2. ROC curve of CYP24A1 in breast cancer cohort. Normal and tumor samples in stage 1, stage 2, stage 3 and stage 4 .

vital status. Patients who were less than 60 years old had higher CYP24A1 expression levels than patients who were more than 60 years old (Fig. 1B). Female patients had higher CYP24A1 expression levels than male patients (Fig. $1 \mathrm{C}, \mathrm{p}=0.039$ ), but further studies need to be performed due to the limited number of male patients. With regard to the molecular subtype, only basal breast cancer had higher CYP24A1 expression compared to normal tissue, while Lum A, HER2 and Lum B had lower CYP24A1 expression compared to normal tissue (Fig. 1D). Positive ER, PR and HER2 groups had lower CYP24A1 expression than negative groups (Fig. 1E-G). As shown in Fig. $1 \mathrm{H}$, indemenopausal, perimenopausal and premenopausal groups had similar CYP24A1 expression, while the postmenopausal group had lower CYP24A1 expression compared to the other groups. CYP24A1 mRNA expression levels of different $\mathrm{T}$ and $\mathrm{N}$ classifications are shown in Fig. 1I,J. Breast cancer with a positive lymph node status had higher CYP24A1 expression than breast cancer with a negative lymph node status (Fig. 1K). Although the $\mathrm{p}$ value was greater than 0.05 , the group with close margin status had higher expression than the negative and positive groups (Fig. 1L). Deceased patients with breast cancer had lower CYP24A1 expression than living patients with breast cancer (Fig. 1M).

Capability of CYP24A1 to diagnose breast cancer. We used the receiver-operating characteristic (ROC) curve of CYP24A1 to analyze the diagnostic capability of CYP24A1. As shown in Fig. 2, a moderate diagnostic ability in breast cancer was observed with the area under the curve (AUC) of 0.678 . We also analyzed the diagnostic capability of CYP24A1 in different stages, and similar results were found with AUC values of 0.651 (stage 1), 0.670 (stage 2), 0.703 (stage 3 ) and 0.760 (stage 4 ), showing a progressive increase with higher stages.

Relationships between clinical characteristics and CYP24A1 expression. We divided the results into two groups based on the medium value for analysis of the relationship between clinical features and CYP24A1 mRNA expression (Table 2). The threshold CYP24A1 level identified from the ROC curve was used to form the low- and high- groups. According to Chi-square tests, low CYP24A1 mRNA expression was highly associated with age, molecular subtype, ER, PR, HER2, menopause status, N classification, vital status, overall survial and relapse-free survival (with $\mathrm{P}$ value $<0.01)$. Moreover, gender $(\mathrm{P}=0.0175)$, histological type $(\mathrm{P}=0.034)$ and neoadjuvant treatment $(\mathrm{P}=0.045)$ were correlated with CYP24A1 expression.

CYP24A1 mRNA expression is correlated with overall survival. As shown in Fig. 3, the KaplanMeier survival curve with the log rank test revealed the relationship between CYP24A1 mRNA expression and overall survival of patients. Low CYP24A1 expression was significantly associated with poor overall survival $(\mathrm{P}<0.0001)$. The subgroup analysis showed that low CYP24A1 expression indicated a poor overall survival of patients with basal $(\mathrm{P}=0.0049)$, HER2 $(\mathrm{P}=0.044)$, Lum $\mathrm{A}(\mathrm{P}=0.11)$ and Lum $\mathrm{B}(\mathrm{P}=0.013)$ breast cancer. Additionally, poor overall survival was associated with HER2-negative tumors, HER2-positive tumors, ER-negative tumors, ER-positive tumors, PR-negative tumors, PR-positive tumors, infiltrating ductal carcinoma and infiltrating lobular carcinoma. Univariate Cox analysis identified critical variables, including age, HER2, 


\begin{tabular}{|c|c|c|c|c|c|c|}
\hline \multirow[b]{2}{*}{ Clinical characteristics } & \multirow[b]{2}{*}{ Variable } & \multirow[b]{2}{*}{ Number } & \multicolumn{2}{|c|}{ CYP24A1 mRNA } & \multirow[b]{2}{*}{$x^{2}$} & \multirow[b]{2}{*}{ P value } \\
\hline & & & High n (\%) & Low n (\%) & & \\
\hline \multirow{2}{*}{ Age } & $<60$ & 589 & $394(60.99)$ & $195(42.76)$ & 35.6946 & 0.0005 \\
\hline & $\geq 60$ & 513 & $252(39.01)$ & $261(57.24)$ & & \\
\hline \multirow{2}{*}{ Gender } & Female & 1090 & $643(99.54)$ & 447 (98.03) & 5.6535 & 0.0175 \\
\hline & Male & 12 & $3(0.46)$ & $9(1.97)$ & & \\
\hline \multirow{3}{*}{ Histological type } & Infiltrating Ductal Carcinoma & 790 & $448(69.46)$ & $342(75)$ & 6.7469 & 0.034 \\
\hline & Infiltrating Lobular Carcinoma & 204 & $136(21.09)$ & $68(14.91)$ & & \\
\hline & Other & 107 & $61(9.46)$ & $46(10.09)$ & & \\
\hline \multirow{5}{*}{ Molecular subtype } & Basal & 142 & $119(24.64)$ & $23(6.28)$ & 99.1391 & 0.0005 \\
\hline & Her2 & 67 & $25(5.18)$ & $42(11.48)$ & & \\
\hline & LumA & 422 & $255(52.8)$ & $167(45.63)$ & & \\
\hline & LumB & 194 & $66(13.66)$ & $128(34.97)$ & & \\
\hline & Normal & 24 & $18(3.73)$ & $6(1.64)$ & & \\
\hline \multirow{3}{*}{ ER } & Indeterminate & 2 & $0(0)$ & $2(0.46)$ & 22.9524 & 0.0005 \\
\hline & \begin{tabular}{|l|} 
Negative \\
\end{tabular} & 239 & $170(27.6)$ & $69(15.75)$ & & \\
\hline & Positive & 813 & $446(72.4)$ & 367 (83.79) & & \\
\hline \multirow{3}{*}{$\mathrm{PR}$} & Indeterminate & 4 & $2(0.33)$ & $2(0.46)$ & 3.8 & 0.1169 \\
\hline & \begin{tabular}{|l} 
Negative \\
\end{tabular} & 345 & $216(35.12)$ & $129(29.45)$ & & \\
\hline & Positive & 704 & 397 (64.55) & 307 (70.09) & & \\
\hline \multirow{4}{*}{ HER2 } & Equivocal & 180 & $100(18.59)$ & $80(20.89)$ & 24.8705 & 0.0005 \\
\hline & Indeterminate & 12 & $5(0.93)$ & $7(1.83)$ & & \\
\hline & Negative & 565 & $362(67.29)$ & $203(53)$ & & \\
\hline & Positive & 164 & $71(13.2)$ & $93(24.28)$ & & \\
\hline \multirow{4}{*}{ Menopause status } & Inde & 34 & $23(3.91)$ & $11(2.6)$ & 15.7947 & 0.0005 \\
\hline & Peri & 40 & $27(4.59)$ & $13(3.07)$ & & \\
\hline & Post & 706 & 382 (64.97) & $324(76.6)$ & & \\
\hline & Pre & 231 & $156(26.53)$ & 75 (17.73) & & \\
\hline \multirow{5}{*}{$\mathrm{T}$ classification } & $\mathrm{T} 1$ & 281 & $179(27.71)$ & $102(22.37)$ & 5.2863 & 0.2354 \\
\hline & $\mathrm{T} 2$ & 640 & $363(56.19)$ & 277 (60.75) & & \\
\hline & T3 & 138 & $82(12.69)$ & $56(12.28)$ & & \\
\hline & $\mathrm{T} 4$ & 40 & $20(3.1)$ & $20(4.39)$ & & \\
\hline & TX & 3 & $2(0.31)$ & $1(0.22)$ & & \\
\hline \multirow{5}{*}{$\mathrm{N}$ classification } & No & 516 & 310 (47.99) & $206(45.18)$ & 13.4385 & 0.0085 \\
\hline & N1 & 367 & $226(34.98)$ & $141(30.92)$ & & \\
\hline & N2 & 120 & $67(10.37)$ & $53(11.62)$ & & \\
\hline & N3 & 79 & $37(5.73)$ & $42(9.21)$ & & \\
\hline & NX & 20 & $6(0.93)$ & $14(3.07)$ & & \\
\hline \multirow{3}{*}{ M classification } & M0 & 917 & $536(82.97)$ & 381 (83.55) & 2.0835 & 0.3573 \\
\hline & M1 & 22 & $10(1.55)$ & $12(2.63)$ & & \\
\hline & MX & 163 & $100(15.48)$ & $63(13.82)$ & & \\
\hline & I & 182 & $117(18.22)$ & $65(14.38)$ & 6.4159 & 0.1599 \\
\hline & II & 626 & $372(57.94)$ & 254 (56.19) & & \\
\hline Stage & III & 252 & $137(21.34)$ & $115(25.44)$ & & \\
\hline & IV & 20 & $9(1.4)$ & $11(2.43)$ & & \\
\hline & $\mathrm{X}$ & 14 & $7(1.09)$ & $7(1.55)$ & & \\
\hline Jymph node status & NO & 28 & $13(3.02)$ & $15(5.08)$ & 2.0026 & 0.1699 \\
\hline Lympn node status & YES & 697 & 417 (96.98) & $280(94.92)$ & & \\
\hline & Close & 31 & $20(3.31)$ & $11(2.58)$ & 2.6135 & 0.2599 \\
\hline Margin status & \begin{tabular}{|l|} 
Negative \\
\end{tabular} & 922 & $545(90.08)$ & 377 (88.29) & & \\
\hline & Positive & 79 & $40(6.61)$ & $39(9.13)$ & & \\
\hline Vital status & Deceased & 155 & $69(10.68)$ & $86(18.86)$ & 14.7927 & 0.0005 \\
\hline Vital status & Living & 947 & 577 (89.32) & 370 (81.14) & & \\
\hline Radiation therany & NO & 445 & $253(42.59)$ & $192(47.06)$ & 1.9543 & 0.1864 \\
\hline Radiation therapy & YES & 557 & $341(57.41)$ & $216(52.94)$ & & \\
\hline Nenadiurant treatment & NO & 1088 & 641 (99.38) & 447 (98.03) & 4.1944 & 0.045 \\
\hline Neoadjuvant treatment & YES & 13 & $4(0.62)$ & $9(1.97)$ & & \\
\hline Continued & & & & & & \\
\hline
\end{tabular}




\begin{tabular}{|c|c|c|c|c|c|c|}
\hline \multirow[b]{2}{*}{ Clinical characteristics } & \multirow[b]{2}{*}{ Variable } & \multirow[b]{2}{*}{ Number } & \multicolumn{2}{|c|}{ CYP24A1 mRNA } & \multirow[b]{2}{*}{$x^{2}$} & \multirow[b]{2}{*}{ P value } \\
\hline & & & High n (\%) & Low n (\%) & & \\
\hline \multirow{2}{*}{ Targeted molecular therapy } & NO & 46 & $24(7.02)$ & $22(9.28)$ & 0.9821 & 0.3538 \\
\hline & YES & 533 & $318(92.98)$ & $215(90.72)$ & & \\
\hline \multirow{2}{*}{ Sample type } & Metastatic & 7 & $4(0.62)$ & $3(0.66)$ & 0.0062 & 1 \\
\hline & Primary Tumor & 1097 & $643(99.38)$ & 454 (99.34) & & \\
\hline \multirow{2}{*}{ Overall survival } & NO & 933 & $568(89.31)$ & $365(80.93)$ & 15.2275 & 0.001 \\
\hline & YES & 154 & $68(10.69)$ & $86(19.07)$ & & \\
\hline \multirow{2}{*}{ Recurrence-free survival } & NO & 816 & $509(92.21)$ & 307 (85.28) & 11.1183 & 0.0005 \\
\hline & YES & 96 & $43(7.79)$ & $53(14.72)$ & & \\
\hline
\end{tabular}

Table 2. Correlation between the expression of CYP24A1 and the clinicopathologic characteristics in breast cancer.

stage, margin status and CYP24A1. The subsequent multivariate analysis (with 1087 patients actually included) validated that age, clinical stage and CYP24A1 expression were independent prognostic factors for overall survival of patients with breast cancer (Table 3 ).

CYP24A1 mRNA expression is associated with relapse-free survival. The Kaplan-Meier survival curve was used for evaluating the relationship between CYP24A1 expression and relapse-free survival (Fig. 4). Similar to the consequences above, low CYP24A1 expression showed a close association with basal tumors, Lum A tumors, Lum B tumors, ER-negative tumors, ER-positive tumors, PR-negative tumors, PR-positive tumors, infiltrating ductal carcinoma and infiltrating lobular carcinoma. Low CYP24A1 expression presented remarkable prognostic value $(\mathrm{P}<0.0001)$. Moreover, univariate Cox analysis was used to select the key prognostic factors (ER, PR, stage, margin status, and CYP24A1), and multivariable analysis was used to adjust the interaction between factors. Furthermore, given that proliferation is a strong prognostic component in ER-positive breast cancer, the correlation between CYP24A1 expression and KI67 (gene MKI67) has been studied. The result showed they are strongly correlated $\left(\mathrm{R}^{2}=0.00219\right.$, Fig. S1). CYP24A1 expression was an independent prognostic factor for patients with breast cancer as confirmed by univariate and multivariate Cox analyses (Table 4, with 912 patients actually included in the multivariable Cox analyses).

\section{Discussion}

Our group has recently been studying biomarkers for prognosis of cancers ${ }^{12-18}$. The present study focused on CYP24A1 mRNA expression and demonstrated the important role of CYP24A1 in breast cancer. Low CYP24A1 expression was associated with age, ER, menopause status, TNM classification, stage, margin status, vital status and radiation therapy. In addition, CYP24A1 expression was an independent prognostic factor of breast cancer, making it a promising biomarker with great potential in the near future. However, in contrast with a previously finding that high CYP24A1 expression is upregulated in tumorous breast tissue ${ }^{6}$, we presented a newfound correlation between low expression of CYP24A1 and poor prognosis. The difference may be due to the different ethnicities of people as the tumor samples in the previously reported experiments were collected from the Imam Khomeini Hospital in Iran ${ }^{6}$. Moreover, the sample sizes may have also contributed to the difference ( 30 vs. 1102 in our study). Although one experiment has suggested that high CYP24A1 expression promotes breast cancer growth ${ }^{7}$, we believe our results and take in vivo and in vitro discrepancies into consideration.

Analysis of malignant and benign breast tumors obtained from patients after surgery has demonstrated CYP24A1 splicing in breast cancer, and the expression of CYP24A1 protein is significantly reduced in cancerous tissue compared to benign tissue ${ }^{19}$. Our result was consistent with this finding and may be attributed to CYP24A1 splicing because different splicing variants would lead to dysfunction of enzymes, in which enzymes only bind substrates but lack catalytic ability, therefore resulting in abnormal vitamin D levels ${ }^{19,20}$. Low CYP24A1 expression indicates that less CYP24A1 enzyme is produced, leading to more active vitamin D. As two previous studies have disagreed with Yao et al., who reported that serum level of vitamin D is associated with lower risk of breast cancer morbidity and mortality, it remains disputable whether vitamin D is good or bad for breast cancer survival $^{21,22}$. The expression of vitamin $\mathrm{D}$ receptor was diminished in malignant breast cancer and shown to correlate with a longer relapse-free survival ${ }^{23,24}$. Active vitamin D form $(1,25 \mathrm{D} 3)$ could induce the expression of CYP24A1 through functional vitamin D receptor ${ }^{25}$. However, breast cancer cells may reduce the expression of vitamin D receptor to resist the anti-proliferative effects by vitamin $\mathrm{D}$ receptor-mediated vitamin $\mathrm{D}$ control ${ }^{23}$. With fewer vitamin D receptors, the inducible expression of CYP24A1 could be limited as well. Survivin suppresses vitamin $\mathrm{D}$, which inhibits cancer cell proliferation, indicating that survivin is an important molecule for the viability of myocytes. Vitamin D inhibits the growth of breast cancer cells. However, considering that breast cancer patients have increased risk for cardiovascular diseases, vitamin D may adversely affect outcomes during the acute phase of cardiovascular conditions, further leading to death caused by noncancer ${ }^{21}$. Because noncancer causes of death are higher than cancer causes of death in breast cancer ${ }^{26}$, we not only focused on the inhibition effect of vitamin $\mathrm{D}$ on breast cancer cells but also considered the influence of vitamin D on cardiovascular and other systems as it is a dilemma to obtain a conclusion that high level of vitamin D benefits patients with breast cancer. This point of view was further supported by a newly published article in The New England Journal of Medicine (Manson et al.), which demonstrated that supplementation with vitamin $\mathrm{D}$ does not result in a lower incidence of invasive cancer or cardiovascular events compared to placebo ${ }^{27}$ with a hazard ratio of 1.02 and $95 \%$ CI of 0.79 to 1.31 


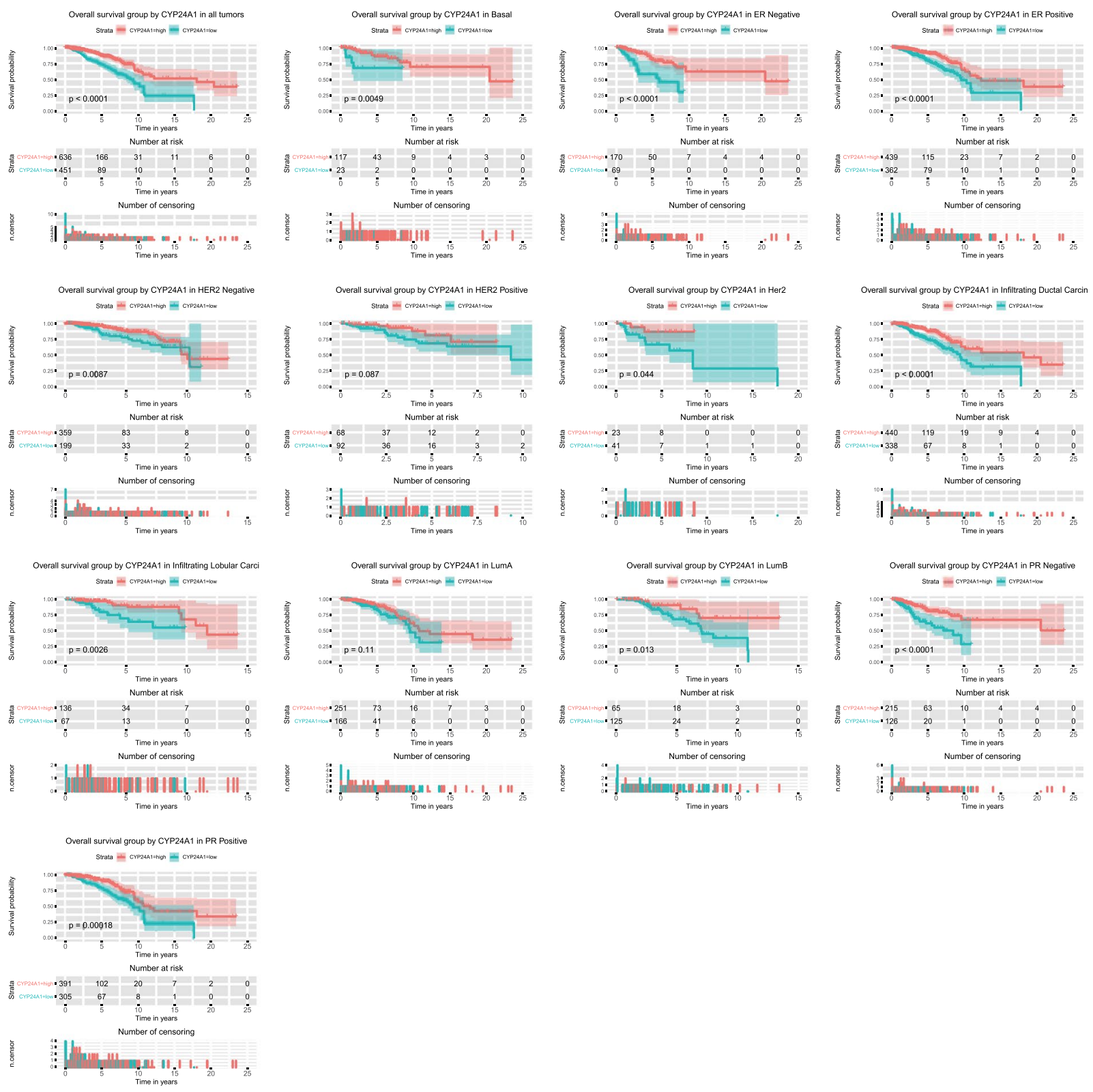

Figure 3. Overall survival analysis of CYP24A1 expression. Kaplan-Meier curves produced overall survival analysis and subgroup analysis of basal, HER2, Lum A, Lum B, HER2-negative tumors, HER2-positive tumors, ER-negative, ER-positive tumors, PR-negative tumors, PR-positive tumors, infiltrating ductal carcinoma and infiltrating lobular carcinoma. The threshold CYP24A1 level identified from the ROC curve was used to form the low- and high- groups.

for breast cancer, indicating no significant difference. Our results were similar to those of that clinical trial as increases in serum vitamin D by intrinsic regulation or extrinsic supplementation may not lower the risk but may be associated with poor prognosis. Similar to results found in other cancers, including lung adenocarcinoma and colorectal cancer ${ }^{10,11,28}$, CYP24A1 may be a promising biomarker in breast cancer. Nevertheless, a consensus has not been reached yet on whether upregulation or downregulation of CYP24A1 leads to poor prognosis when considering the inconclusive function of high vitamin D. Many studies investigated the prognostic role of KI67 in breast cancer and found an increasing value with more evidence ${ }^{29}$. In prognosis, a KI67 level above 10-14\% has been suggested to define a group with high risk ${ }^{29}$. Proliferation is a strong prognostic component in ER-positive breast cancer and the strong correlation between CYP24A1 expression and KI67 could possibly further suggest the prognostic value of CYP24A1.

To the best of our knowledge, this is the first study to investigate the correlation between CYP24A1 mRNA expression and prognosis of breast cancer using meta-analysis on a relatively extensive scale. The present study sheds light on the important role of CYP24A1 in breast cancer. However, based on the complexity of the role of vitamin D in breast cancer, the specific function of CYP24A1 needs to be further elucidated by clinical trials in the future. 


\begin{tabular}{|l|l|l|l|l|l|l|}
\hline \multirow{2}{*}{ Parameters } & \multicolumn{3}{|l|}{ Univariate analysis } & \multicolumn{3}{l|}{ Multivariate analysis } \\
\cline { 2 - 8 } & $\begin{array}{l}\text { Hazard } \\
\text { ratio }\end{array}$ & $\mathbf{9 5 \%} \mathbf{C I}$ & $\mathbf{P}$ value & $\begin{array}{l}\text { Hazard } \\
\text { ratio }\end{array}$ & $\mathbf{9 5 \%}$ CI & P value \\
\hline Age & 1.91 & $1.39-2.63$ & $\mathbf{0 . 0 0 0}$ & 1.95 & $1.21-3.14$ & $\mathbf{0 . 0 0 6}$ \\
\hline Histological type & 0.93 & $0.74-1.17$ & 0.543 & & & \\
\hline Molecular subtype & 1.01 & $0.88-1.16$ & 0.901 & & & \\
\hline ER & 0.85 & $0.71-1.02$ & 0.074 & & & \\
\hline PR & 0.87 & $0.73-1.03$ & 0.096 & & & \\
\hline HER2 & 1.29 & $1.05-1.57$ & $\mathbf{0 . 0 1 3}$ & 1.11 & $0.89-1.38$ & 0.372 \\
\hline Menopause status & 1.16 & $0.94-1.43$ & 0.165 & & & \\
\hline Stage & 1.64 & $1.4-1.91$ & $\mathbf{0 . 0 0 0}$ & 2.16 & $1.64-2.85$ & $\mathbf{0 . 0 0 0}$ \\
\hline Lymph node status & 1.1 & $0.93-1.3$ & 0.274 & & & \\
\hline Margin status & 1.42 & $1.11-1.81$ & $\mathbf{0 . 0 0 5}$ & 0.97 & $0.69-1.36$ & 0.858 \\
\hline CYP24A1 & 2.4 & $1.73-3.31$ & $\mathbf{0 . 0 0 0}$ & 2.01 & $1.25-3.25$ & $\mathbf{0 . 0 0 4}$ \\
\hline
\end{tabular}

Table 3. Summary of univariate and multivariate Cox regression analyses of overall survival duration.
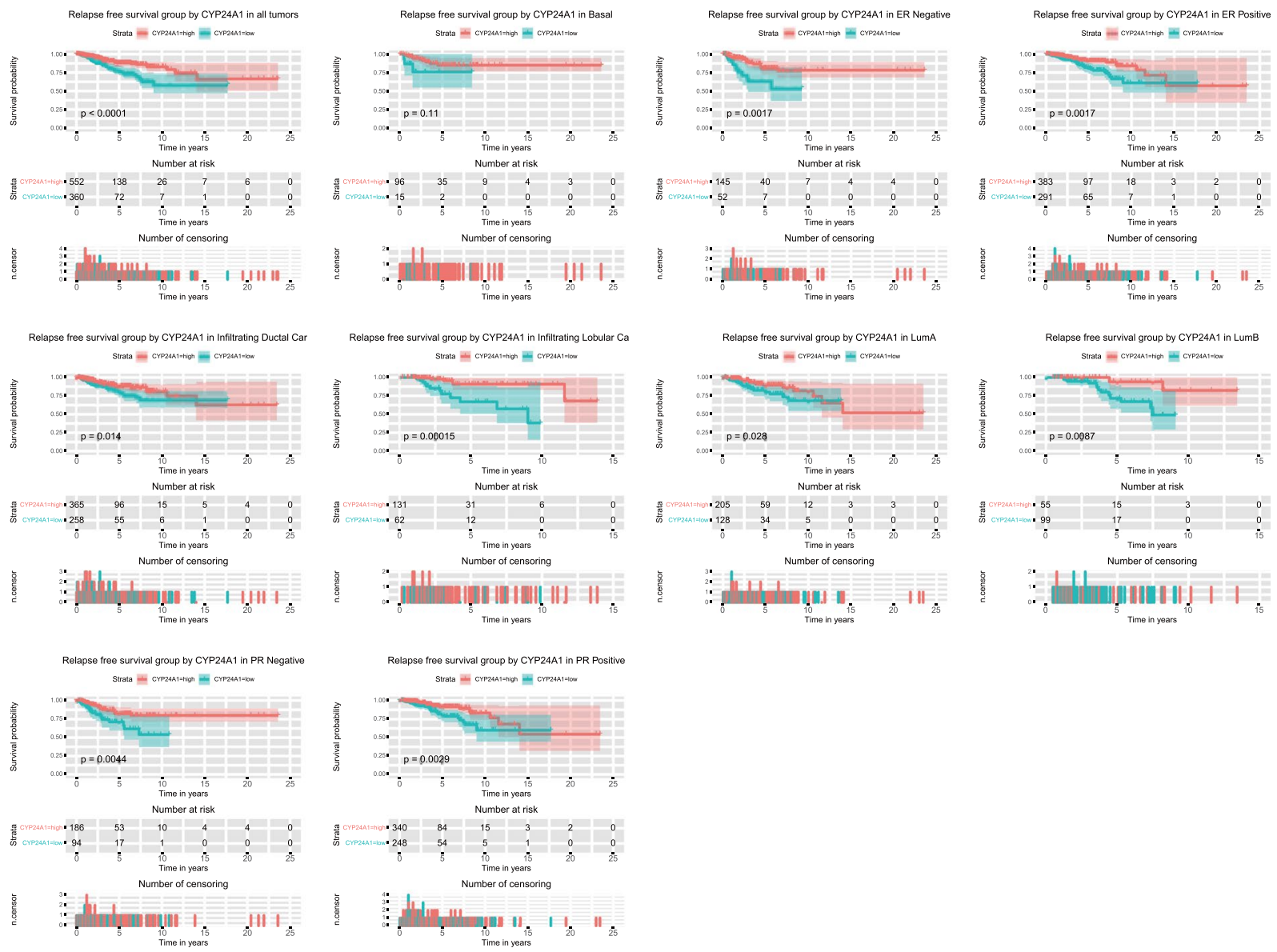

Figure 4. Relapse-free survival analysis of CYP24A1 expression. Kaplan-Meier curves produced relapse-free survival analysis and subgroup analysis of basal tumors, Lum A tumors, Lum B tumors, ER-negative tumors, ER-positive tumors, PR-negative tumors, PR-positive tumors, infiltrating ductal carcinoma and infiltrating lobular carcinoma. The threshold CYP24A1 level identified from the ROC curve was used to form the low- and high- groups.

\section{Materials and Methods}

Data collection from TCGA database. The RNA expression data was downloaded from the Cancer Genome Atlas (https://cancergenome.nih.gov/) and was shown in RSEM normalized count transformed through calculation using $\log 2(x+1)$. The clinicopathological details and related information of breast cancer patients were also collected. This study enrolled 1102 patients, including 1090 females and 12 males, with 589 patients 


\begin{tabular}{|l|l|l|l|l|l|l|}
\hline \multirow{2}{*}{ Parameters } & \multicolumn{3}{l}{ Univariate analysis } & \multicolumn{2}{ll}{ Multivariate analysis } & \multicolumn{2}{l|}{$\begin{array}{l}\text { Hazard } \\
\text { ratio }\end{array}$} & 95\% CI & P value \\
\cline { 2 - 7 } & ratio & $\mathbf{9 5 \%}$ CI & P value & & \\
\hline Age & 1.45 & $0.97-2.16$ & 0.072 & & & \\
\hline Histological type & 0.86 & $0.65-1.14$ & 0.29 & & & \\
\hline ER & 0.99 & $0.82-1.2$ & 0.945 & & $0.54-1.03$ & 0.075 \\
\hline PR & 0.78 & $0.63-0.97$ & $\mathbf{0 . 0 2 6}$ & 0.74 & $0.64-1.17$ & 0.345 \\
\hline HER2 & 0.78 & $0.64-0.96$ & $\mathbf{0 . 0 1 9}$ & 0.87 & & \\
\hline Menopause status & 0.93 & $0.7-1.22$ & 0.596 & & & \\
\hline Stage & 0.95 & $0.74-1.22$ & 0.713 & & $1.31-2.05$ & $\mathbf{0 . 0 0 0}$ \\
\hline Lymph node status & 1.71 & $1.4-2.08$ & $\mathbf{0 . 0 0 0}$ & 1.64 & & \\
\hline Margin status & 0.86 & $0.7-1.06$ & 0.159 & & & \\
\hline CYP24A1 & 1.59 & $1.23-2.06$ & $\mathbf{0 . 0 0 0}$ & 1.43 & $1.09-1.88$ & $\mathbf{0 . 0 0 9}$ \\
\hline
\end{tabular}

Table 4. Summary of univariate and multivariate Cox regression analyses of relapse-free survival duration.

younger than 60 years old. The average follow-up time of patients for overall survival and relapse-free survival is 1261.6 days and 1262.8 days respectively, and the number of events was 154 .

Statistical analysis. For discrete variables, we utilized boxplots to measure the differences of expression by ggplot2 package in R. ROC analysis was performed using R package pROC and Cox regression was performed using R package Survival. SPSS software (Version 19.0) was used to investigate the correlation between CYP24A1 expression and clinical characteristics of breast cancer using Chi-square tests. To compare the overall survival in both groups (high vs. low), Kaplan-Meier curves were used, and P values were calculated. Univariate Cox analysis was performed for selection of related variables. The procedure was repeated for relapse-free survival analysis.

\section{Data Availability}

All data is available.

\section{References}

1. Harbeck, N. \& Gnant, M. Breast cancer. The Lancet 389, 1134-1150, https://doi.org/10.1016/s0140-6736(16)31891-8 (2017).

2. Duffy, M. J., Walsh, S., McDermott, E. W. \& Crown, J. Biomarkers in Breast Cancer: Where Are We and Where Are We Going? Advances in clinical chemistry 71, 1-23, https://doi.org/10.1016/bs.acc.2015.05.001 (2015).

3. Feldman, D., Krishnan, A. V., Swami, S., Giovannucci, E. \& Feldman, B. J. The role of vitamin D in reducing cancer risk and progression. Nature reviews. Cancer 14, 342-357, https://doi.org/10.1038/nrc3691 (2014).

4. Huss, L. et al. Serum levels of vitamin D, parathyroid hormone and calcium in relation to survival following breast cancer. Cancer causes \& control: CCC 25, 1131-1140, https://doi.org/10.1007/s10552-014-0413-3 (2014).

5. Welsh, J. Function of the vitamin D endocrine system in mammary gland and breast cancer. Molecular and cellular endocrinology 453, 88-95, https://doi.org/10.1016/j.mce.2017.04.026 (2017).

6. Zhalehjoo, N., Shakiba, Y. \& Panjehpour, M. Gene expression profiles of CYP24A1 and CYP27B1 in malignant and normal breast tissues. Molecular medicine reports 15, 467-473, https://doi.org/10.3892/mmr.2016.5992 (2017).

7. Osanai, M. \& Lee, G. H. CYP24A1-induced vitamin D insufficiency promotes breast cancer growth. Oncology reports 36, 2755-2762, https://doi.org/10.3892/or.2016.5072 (2016).

8. Carpenter, T. O. CYP24A1 loss of function: Clinical phenotype of monoallelic and biallelic mutations. The Journal of steroid biochemistry and molecular biology 173, 337-340, https://doi.org/10.1016/j.jsbmb.2017.01.006 (2017).

9. Welsh, J. Vitamin D and breast cancer: Past and present. The Journal of steroid biochemistry and molecular biology 177, 15-20, https://doi.org/10.1016/j.jsbmb.2017.07.025 (2018).

10. Shiratsuchi, H. et al. Oncogenic Potential of CYP24A1 in Lung Adenocarcinoma. Journal of thoracic oncology: official publication of the International Association for the Study of Lung Cancer 12, 269-280, https://doi.org/10.1016/j.jtho.2016.10.010 (2017).

11. Sun, H. et al. CYP24A1 is a potential biomarker for the progression and prognosis of human colorectal cancer. Human pathology $\mathbf{5 0}$, 101-108, https://doi.org/10.1016/j.humpath.2015.11.008 (2016).

12. Li, Y. et al. High miR-454-3p expression predicts poor prognosis in hepatocellular carcinoma. Cancer management and research 11 , 2795-2802, https://doi.org/10.2147/CMAR.S196655 (2019).

13. Jiao, Y., Fu, Z., Li, Y., Meng, L. \& Liu, Y. High EIF2B5 mRNA expression and its prognostic significance in liver cancer: a study based on the TCGA and GEO database. Cancer management and research 10,6003-6014, https://doi.org/10.2147/CMAR.S185459 (2018).

14. Jiao, Y., Li, Y., Lu, Z. \& Liu, Y. High Trophinin-Associated Protein Expression Is an Independent Predictor of Poor Survival in Liver Cancer. Digestive diseases and sciences 64, 137-143, https://doi.org/10.1007/s10620-018-5315-X (2019).

15. Jiao, Y., Fu, Z., Li, Y., Zhang, W. \& Liu, Y. Aberrant FAM64A mRNA expression is an independent predictor of poor survival in pancreatic cancer. PloS one 14, e0211291, https://doi.org/10.1371/journal.pone.0211291 (2019).

16. Jiao, Y., Li, Y., Jiang, P., Han, W. \& Liu, Y. PGM5: a novel diagnostic and prognostic biomarker for liver cancer. PeerJ 7, e7070, https:// doi.org/10.7717/peerj.7070 (2019).

17. Jiao, Y., Li, Y., Liu, S., Chen, Q. \& Liu, Y. ITGA3 serves as a diagnostic and prognostic biomarker for pancreatic cancer. OncoTargets and therapy 12, 4141-4152, https://doi.org/10.2147/ott.S201675 (2019).

18. Hou, L. et al. ATP binding cassette subfamily B member 9 (ABCB9) is a prognostic indicator of overall survival in ovarian cancer. Medicine (Baltimore) 98, e15698, https://doi.org/10.1097/MD.0000000000015698 (2019).

19. Chimi Scheible, M. T., Baum, S., Solomayer, E. \& Friedrich, M. Implication of CYP24A1 Splicing in Breast Cancer. Anti-Cancer Agents in Medicinal Chemistry 14, 109-114 (2014).

20. Horvath, H. C. et al. CYP24A1 splice variants-implications for the antitumorigenic actions of $1,25-(\mathrm{OH}) 2 \mathrm{D} 3$ in colorectal cancer. The Journal of steroid biochemistry and molecular biology 121, 76-79, https://doi.org/10.1016/j.jsbmb.2010.03.080 (2010).

21. Mormile, R. Vitamin D and Breast Cancer Survival: The Good and the Bad. JAMA oncology 3, 1138, https://doi.org/10.1001/ jamaoncol.2016.6588 (2017). 
22. Braillon, A. Vitamin D and Breast Cancer Survival: The Good and the Bad. JAMA oncology 3, 1138-1139, https://doi.org/10.1001/ jamaoncol.2016.6792 (2017).

23. Nair Lopes, B. S. et al. Alterations in Vitamin D signalling and metabolic pathways in breast cancer progression: a study of VDR, CYP27B1 and CYP24A1 expression in benign and malignant breast lesions Vitamin D pathways unbalanced in breast lesions. BMC Cancer 10, 483 (2010).

24. Richards, S. E., Weierstahl, K. A. \& Kelts, J. L. Vitamin D Effect on Growth and Vitamin D Metabolizing Enzymes in Triple-negative Breast Cancer. Anticancer Research 35, 805-810 (2015).

25. Diesing, D., Cordes, T., Fischer, D., Diedrich, K. \& Friedrich, M. Vitamin D - Metabolism in the Human Breast Cancer Cell Line MCF-7. Anticancer Research (2006).

26. Zaorsky, N. G. et al. Causes of death among cancer patients. Annals of oncology: official journal of the European Society for Medical Oncology 28, 400-407, https://doi.org/10.1093/annonc/mdw604 (2017).

27. Manson, J. E. et al. Vitamin D Supplements and Prevention of Cancer and Cardiovascular Disease. New England Journal of Medicine 380, 33-44, https://doi.org/10.1056/NEJMoa1809944 (2019).

28. Horvath, H. C. et al. The candidate oncogene CYP24A1: A potential biomarker for colorectal tumorigenesis. The journal of histochemistry and cytochemistry: official journal of the Histochemistry Society 58, 277-285, https://doi.org/10.1369/jhc.2009.954339 (2010).

29. Yerushalmi, R., Woods, R., Ravdin, P. M., Hayes, M. M. \& Gelmon, K. A. Ki67 in breast cancer: prognostic and predictive potential. Lancet Oncology 11, 174-183 (2010).

\section{Acknowledgements}

This study was supported by Science and Technology of Jilin Province Health and Family Planning Commission Project 2017Q035 (Z.Y.).

\section{Author Contributions}

H.C. designed this paper. Y.J. provided concepts. H.C., Y.J., Y.L., Z.Y. and M.H. did the analysis. H.C. and Y.J. drafted. Y.L. and Z.Y. revised this paper.

\section{Additional Information}

Supplementary information accompanies this paper at https://doi.org/10.1038/s41598-019-50214-z.

Competing Interests: The authors declare no competing interests.

Publisher's note Springer Nature remains neutral with regard to jurisdictional claims in published maps and institutional affiliations.

(c) (1) Open Access This article is licensed under a Creative Commons Attribution 4.0 International

License, which permits use, sharing, adaptation, distribution and reproduction in any medium or format, as long as you give appropriate credit to the original author(s) and the source, provide a link to the Creative Commons license, and indicate if changes were made. The images or other third party material in this article are included in the article's Creative Commons license, unless indicated otherwise in a credit line to the material. If material is not included in the article's Creative Commons license and your intended use is not permitted by statutory regulation or exceeds the permitted use, you will need to obtain permission directly from the copyright holder. To view a copy of this license, visit http://creativecommons.org/licenses/by/4.0/.

(C) The Author(s) 2019 